\title{
Pasado inconcluso. Las tensiones entre la historia y la memoria bajo el signo del exilio
}

\author{
Unfinished Past. The Tensions Between History \\ and Memory Under the Sign of Exile
}

\author{
Antolín SÁnchez Cuervo
}

Instituto de Filosofía, CCHS-CSIC

RESUMEN. La creciente relevancia de la memoria en toda aproximación al pasado ha obligado a la historia a ofrecer respuestas a sus preguntas, objeciones y ambigüedades, más allá de los tópicos historicistas. Incluso cabe plantear una "historia anamnética", inspirada en las aportaciones de la memoria crítica o benjaminiana, que además encuentra en la experiencia del exilio motivos de reflexión muy fecundos. Ciertos escritos de María Zambrano constituyen un buen ejemplo de esta fecundidad.

Palabras clave: Historia, memoria, conocimiento del pasado, exilio, Walter Benjamin, María Zambrano.

1. En un libro reciente dedicado a las relaciones entre la historia y la memoria, el historiador Geoffrey Cubitt subraya el "giro hacia la memoria» ${ }^{1}$ característico de las nuevas aproximaciones al pasado desde la historia, entre otras disciplinas tales como la sociología, la antropología y los estudios culturales. Durante el último cuarto de siglo - apunta en este sentido - la memoria se habría erigido en una categoría analítica y discursiva indispensable para el conocimiento del pasado, «para explorar el sutil proceso transformador por el que la historia vivida y la
ABSTRACT. The growing importance of memory in all approximation to past has obligated history to give answers to their questions, objections and ambiguities, beyond historicist topics. Also is pertinent to try an «anamnestic history», inspired in the contributions of critical or benjaminian memory, that moreover finds in the experience of exile very fertile motives of reflexion. Certain writings of María Zambrano are a good example of this fecundity.

Key words: History, memory, knowledge of past, exile, Walter Benjamin, María Zambrano.

historia escrita se influyen recíprocamente», para captar «una peculiar fluidez entre el pasado y el presente que la historia convencional o profesional tiende a excluir, o una conexión o continuidad más íntima entre la experiencia del pasado y la conciencia presente». La memoria aludiría entonces a una experiencia compleja y polisémica, de difícil acotación conceptual, inscrita tanto en el ámbito individual como en el de las relaciones sociales, así como del medio cultural y de la trama institucional en la que estos ámbitos se insertan. Sería condición de posibi- 
lidad de la ciencia histórica y constituiría una experiencia insoslayable en cualquier empeño por reconstruir el pasado, incluso cuando éste aparece tamizado bajo el marchamo de la objetividad científica. Las aproximaciones de los historiadores al estudio del pasado — afirma Cubitt - «están influenciadas por lo que ellos mismos recuerdan, interviniendo la memoria en numerosos niveles tanto de la información contenida en las fuentes del material histórico como en las ideas que condicionan la manera en que esos materiales son interpretados». ${ }^{2}$

Ciertamente, la memoria se ha erigido en las últimas décadas en una referencia interdisciplinar imprescindible a la hora de plantear cualquier aproximación al pasado, y no sólo como respuesta a la aceleración de la historia o al vértigo de los cambios acontecidos en la era de la globalización y del pensamiento único, con la consiguiente amenaza para la continuidad e incluso existencia de múltiples identidades que asisten a su propio desarraigo, tal y como ha apuntado Pierre Norá a propósito de los «lugares de la memoria» de la nación francesa ${ }^{3}$. Además de señalar una coyuntura actual, esta apreciación participa de un cambio epocal en el pensamiento crítico cuyo eje es la memoria entendida como experiencia reveladora de una violencia que, cifrada en el olvido, podía legitimarse a través de la racionalidad científica y moral hasta no hace mucho. Desde la sociología de Halbwachs y la filosofía de la historia de Benjamin, por citar dos referencias fundamentales, la memoria ya no es sólo el gran recurso del tradicionalismo o de la reacción contra el criticismo ilustrado, sino también el reconocimiento de un pasado que había permanecido oculto para unos y otros, ya fuera porque en un caso pesara únicamente la tradición revelada por la religión y transmitida a través de instancias acríticas, o porque en el otro ningún elemento tradicional pudiera caber en la lógica del progreso. La memoria es entonces una experiencia colectiva que impregna la acción humana en todas sus facetas y que además descubre una singular capacidad crítica en la rememoración del pasado insatisfecho, hasta el punto de erigirse en el nervio de una nueva teoría del conocimiento y una nueva concepción de la moral, la política y la justicia. La significación epistemológica del testimonio, la consideración del sufrimiento como condición de toda verdad y del recuerdo de las víctimas como un deber, la introducción en la política de conceptos como el de responsabilidad histórica o el reconocimiento del derecho a la reparación por injusticias cometidas en el pasado, expresan el auge de una cultura de la memoria que echó raíces en el período de entreguerras y tocó sus propios límites en torno a la experiencia de Auschwitz, y cuya dimensión es hoy global. ${ }^{4}$ La memoria reabre en la actualidad multitud de expedientes que el derecho consideraba archivados, según una conocida expresión benjaminiana, desde los que durante siglos se han ido acumulando a costa de la violencia esclavista y colonizadora de las potencias europeas, hasta los que, más recientemente, han registrado la represión ejercida por regímenes totalitarios o la violencia terrorista.

Esto no significa que la cultura de la memoria sea la panacea sin más para los problemas de la humanidad, que sus planteamientos estén exentos de paradojas y ambigüedades, lagunas e inmadureces, que no tropiece con múltiples resistencias de toda índole o que no sea susceptible de instrumentalizarse al servicio de intereses concretos o conforme a los criterios de la espectacularidad, banalización y consumo propios de la industria cultural. De hecho, la anterior alusión a la obra colectiva dirigida por Norá puede servirnos para advertir no sólo esta cultu- 
ra de la memoria en auge, sino también la dominación de una cultura diametralmente opuesta, inspirada en la aceleración y por tanto el olvido, en la que pervive la mitología moderna del progreso. La cultura de la memoria convive conflictivamente con esta última, contra la que de hecho se rebela.

Qué duda cabe, en cualquier caso, de que el nuevo horizonte reflexivo despejado por los planteamientos de la memoria comprende también el ámbito de la historia. Esta ya no puede prescindir de la memoria, conformarse con señalar sus peligros, excesos y debilidades, confinarla en los estratos «acientíficos» o «pre-científicos» del análisis del pasado; o reconocerla, en el mejor de los casos, como un mero instrumento historiográfico o un fenómeno histórico erigido en objeto de una investigación particular — la historia de la memoria, como la que Norá plantea-, aun cuando esto último sea muy loable. La historia también está llamada a ofrecer respuestas complejas a las preguntas de la memoria cuando cuestiona su autoridad exclusiva sobre el pasado. Por eso ambas miradas se entrecruzan y elaboran mutuamente en la búsqueda de un pasado que se resiste a ser naturalizado o asimilado en términos de una realidad fáctica y muerta, supuestamente reflejada o representada en multitud de fuentes documentales que aguardan a ser desempolvadas para engrosar la erudición historiográfica. Una reconstrucción del pasado a la altura de este cambio epocal exige, por lo pronto, dos tareas fundamentales:

En primer lugar, que el historiador dé cuenta no sólo de los acontecimientos que han acaecido, sino también de cómo éstos han pervivido en multitud de memorias, de cómo éstas se han transmitido y expresado, qué marcos sociales las han configurado y qué significación política han tenido, por qué en unos casos se han mantenido vivas y en otros se han visto desplazadas o silenciadas, o de cómo han evolucionado e incidido en el propio curso de los acontecimientos. ${ }^{5}$ Esto no significa solamente advertir y analizar las alteraciones, deformaciones y mitificaciones que el pasado ha podido sufrir a lo largo de su transmisión memorial, los mecanismos de selección e interpretación que caracterizan a esta última, los resentimientos y usos partidistas que la pueden alimentar o los factores generacionales e identitarios - muchos de ellos de orden emotivo e irreflexivo- que la condicionan, sometiéndola a multitud de filtros subjetivos, tanto individuales como colectivos. Según este punto de vista, la memoria puede revestir una gran importancia sociológica, antropológica o psicológica, pero difícilmente podrá contribuir al conocimiento del pasado. Todo lo contrario - afirmarán los partidarios de este punto de vista-, pues está construida a base de arbitrariedades y contingencias que velan o distorsionan toda aproximación objetiva a ese pasado. Ahora bien, una reconstrucción compleja del pasado exige también otra mirada, capaz de distinguir en la memoria un continente de experiencias que han sido excluidas, silenciadas, omitidas o reducidas por la disciplina historiográfica, poniendo así en juego otras maneras de plantear el conocimiento histórico. Dicho de otra forma, esas experiencias, irreductibles a los cánones metodológicos y las estrategias discursivas de la historiografía convencional o tradicional ${ }^{6}$, señalan los olvidos en que ha podido incurrir esta última, derivados de su complicidad con las memorias dominantes y oficiales o de sus reduccionismos científicos, dando lugar a una objetividad sin sujeto crítico. La memoria adquiere entonces el carácter de una pregunta que, si es escuchada, obliga al historiador a poner bajo sospecha su propio método y a rehabilitar experiencias que habían sido declaradas irrelevan- 
tes por su condición subjetiva. La memoria compete entonces al historiador no sólo como un fenómeno histórico o como el objeto de una historiografía particular, sino también como una fuente histórica insustituible, capaz de aportar un conocimiento interno e inmediato del pasado frente a la exterioridad y las mediaciones epistemológicas del análisis historiográfico.

Esa fuente es, en primera instancia, el testimonio que emana de las memorias individuales, las cuales confluyen en determinados grupos que van construyendo relatos comunes sobre el pasado a partir del intercambio entre ellas y de la información acumulada sobre ese pasado. Esos relatos constituyen las memorias sociales o colectivas, algunas de las cuales serán mayoritarias o hegemónicas, llegando a competir con las memorias institucionales u oficiales - aquéllas que gozan del respaldo de las políticas de la memoria vigentes - A su vez, esas memorias sociales o colectivas se convertirán en memorias históricas a medida que vayan desapareciendo los testigos directos del pasado rememorado. ${ }^{7}$ La memoria constituye así una fuente compleja y plural sobre el pasado, que al mismo tiempo condiciona el análisis del historiador, siempre subordinado a sus propias memorias, tanto individuales como colectivas. La inteligencia del historiador no es una especie de tábula rasa en la que los hechos del pasado se van registrando y acumulando, de manera imperfecta pero científica, sino que está moldeada por las memorias que impregnan su presente, con las que su propia memoria individual interactúa y que, consecuentemente, condicionan $-\mathrm{y}$ fecundan- su selección e interpretación de esos hechos. Por eso una reconstrucción compleja del pasado está llamada, en segundo lugar, a asumir esta sincronía o esta presencia de múltiples pasados en el presente del suje- to que lo reconstruye. Si además aceptamos que la historia es un proceso de construcción más que de representación ${ }^{8}$, en el que la legibilidad de las fuentes y de los hechos del pasado siempre está mediatizada por multitud de redes discursivas y simbólicas, habrá que contar con la memoria a la hora de identificar estas mediaciones. Si el pasado no es una realidad dada sin más, susceptible de ser aprehendida y representada con una precisión creciente bajo la lente analítica del historiador, sino una experiencia cuya legibilidad depende de su propia construcción desde los intereses, las necesidades, los imaginarios y los prejuicios que configuran un determinado presente, las memorias de esa experiencia que se han ido transmitiendo a lo largo del tiempo no podrán ser ajenas a ese proceso constructivo. La memoria rehabilita así el peso hermenéutico del presente del historiador, mismo que permanece oculto cuando la aproximación al pasado discurre en nombre de una supuesta objetividad ajena al tiempo y al lugar desde el que se piensa y reconstruye ese pasado. En este sentido, la memoria es condición de posibilidad de la historia. Es decir, la historia forma parte de la memoria colectiva, la cual moldea y al mismo tiempo acoge, en un constante vaivén de complicidades y conflictos, identificaciones y alteraciones, la memoria individual del historiador. La disciplina histórica - señala Le Goff en este sentido- se inscribe «en el gran proceso dialéctico de memoria y olvido que viven los individuos y las sociedades», aunque sea misión del historiador «dar cuenta de estos recuerdos y olvidos, para transformarlos en una materia pensable, para hacer de ellos un objeto de saber». ${ }^{9}$ Por eso — apunta asimismo Hobsbawm - «existe una zona de sombra» entre la historia y la memoria, «entre el pasado como registro generalizado, susceptible de un examen relativamente 
desapasionado, y el pasado como una parte recordada o como trasfondo de la propia vida del individuo», que constituye «la parte de la historia más difícil de comprender» y que pone en juego dos conceptos diferentes de ella: «el erudito y el existencial, los archivos y la memoria personal» ${ }^{10}$. Dos conceptos que, precisamente porque su diferencia no se salda sencillamente en que uno aprehende el pasado de manera objetiva y fiable mientras que el otro lo hace de manera subjetiva y tendenciosa, están abocados a la reciprocidad y al entrelazamiento problemático. En la subjetividad del recuerdo puede esconderse un conocimiento del pasado que escapa al análisis del historiador, cuya objetividad puede esconder, a su vez, un peso subjetivo mayor del que pudiera aparentar.

Ningún conocimiento del pasado escapa por tanto a las mediaciones de la memoria, tal y como la propia teoría de la historia ha ido constatando a lo largo de las últimas décadas, aun desde perspectivas diversas y bajo una rica variedad de matices y puntos da vista, atribuyendo a esas mediaciones una relevancia mayor o menor. Tanto la microhistoria italiana como la historia social británica, las últimas generaciones de los Anales, la nueva historia cultural o la historia oral, por poner sólo algunos ejemplos, han registrado de alguna manera el cambio epocal introducido por la memoria en la racionalidad contemporánea. De unas formas u otras, bajo unos enfoques y desde unos bagajes $\mathrm{u}$ otros, han ofrecido respuestas complejas a la gran ambigüedad que preside las relaciones entre la historia y la memoria: lo primero aspira a una visión crítica, objetiva y secular de un pasado del que al mismo tiempo se distancia y cuya legibilidad está altamente condicionada por multitud de filtros - las memorias entre ellos - Lo segundo persigue un conocimiento directo e irreductible de un pasa- do que no deja de exponerse a la alteración, la deformación y la mitificación. En cualquier caso, ningún planteamiento de la historia a la altura de dicho cambio epocal podrá despachar la memoria como un pseudo-conocimiento del pasado sin más, como un obstáculo acientífico o una interferencia subjetiva en el camino hacia la objetividad, o como una mera fuente de distorsiones y mitificaciones de la realidad al servicio de ideologías sectarias o de resentimientos que coartan la supuesta misión educadora de la historia. Es obvio que la memoria puede acarrear estos peligros y que es altamente manipulable, pero sólo una visión simplista e ingenua del pasado podría satisfacerse con esta sola apreciación. Frente a este simplismo, la memoria se significa también por su relevancia en la transmisión plural de un pasado que condiciona la propia escritura de la historia, y su capacidad para aportar un conocimiento del mismo que a menudo escapa a la lente analítica del historiador. La memoria asoma por todas las caras de Clío.

2. ¿Esto es todo lo que se puede decir sobre la significación de la memoria en la reconstrucción del pasado? ¿son estos sus límites frente a la historia? Después de todo, aun a pesar de la relación de reciprocidad que acabamos de perfilar, pareciera como si la memoria no dejara de ser un recurso heurístico al servicio del historiador, el cual seguiría teniendo la última palabra sobre el pasado, aun cuando para ello necesitara ponerse al día y rectificar cuanto fuera necesario sus métodos convencionales y sus bagajes positivistas. Que la memoria sea un ingrediente esencial tanto del pasado y del presente como de la mediación entre uno y otro, o que incluso sea condición de posibilidad de la historia, son hechos perfectamente asumibles por cualquier historiador que sepa situarse a la altura de los tiempos, sin perder por ello su status a 
la hora de relacionarse con el pasado. Un historiador receptivo a las preguntas de la memoria como Jaques Le Goff, por ejemplo, parece insinuar esta primacía cuando afirma que «la memoria es la materia prima de la historia» ${ }^{11}$; y algo similar le sucede a Paul Ricoeur cuando distingue entre «fenomenología de la memoria» y «epistemología de la historia», reservando para esta última una escritura plenamente madura del pasado, aun cuando ésta se inicie ya en el registro del testimonio. ${ }^{12}$ Es decir, pareciera como si el conocimiento del pasado que proporciona la memoria fuera, pese a su singularidad y su relevancia, rudo e irreflexivo, o como si precisara de una factura historiográfica que certificara sus aportaciones. Sería por ello una «materia prima», imprescindible para la construcción de la historia, pero difícilmente reconocible al final del proceso; o una «fenomenología» que discierne un punto de partida apodíctico para dicho proceso, pero cuya culminación epistemológica sería asunto de la historia. El propio Norá tampoco deja de ser ambiguo al respecto. Por una parte señala que la historia, al volverse crítica y reflexiva al calor de la actual cultura de la aceleración, ha roto los vínculos con la memoria —identificada con «la vida»que en otras épocas le permitía una relación equilibrada con el pasado. Hasta tal punto, que la historia «es lo que hacen del pasado nuestras sociedades condenadas al olvido» y «la deslegitimación del pasado vivido», y cuya aspiración no puede ser por tanto «la exaltación de lo que ha pasado verdaderamente, sino su aniquilación»». Pero, por otra parte — añade Norá-, esa vitalidad propia de la memoria, por medio de la que el pasado permanece siempre ligado al presente, no deja de ser «afectiva y mágica», vulnerable a la deformación y la manipulación o vaga y ancestral. ${ }^{13}$

¿No cabría, sin embargo, un planteamiento de la memoria más ambicioso o más crítico? Si estamos hablando de un cambio epocal del que la memoria es responsable, ¿no cabría esperar algo más de ella?

En su citado libro, Cubitt señala algo en este sentido, aunque muy escuetamente y sin llegar a desarrollarlo, a propósito de la opinión que defiende la primacía de la memoria «(forma de conocimiento auténtica e inmediata)» sobre la historia «(una combinación incierta de conjeturas retrospectivas y de ilusiones)». A su juicio, un énfasis político en este contraste conduciría a una desmitificación de la historia en términos de una narración opresora o «una construcción reputada y autoritaria del pasado al servicio de los intereses de la élites, que excluye o margina otras experiencias», mientras que la memoria designaría «las voces múltiples y desorganizadas, pero siempre potencialmente resurgentes, de los marginados y excluidos.» ${ }^{14}$ La memoria no sólo sería entonces una potente correa de transmisión de las experiencias del pasado, desde un determinado entonces hasta el presente del historiador - algo que no deja de ser abstracto y general-, sino también, y sobre todo, aquello que permite rescatar un ámbito muy singular de ese pasado; aquél, concretamente, que ha permanecido desplazado y silenciado bajo el peso de las memorias y las reconstrucciones historiográficas dominantes, $\mathrm{y}$ que ha sido declarado insignificante por ellas. Es decir, ese pasado desplazado no sería sólo un ingrediente más del pasado transmitido a través de la memoria, sino que constituiría, por su relevancia crítica, el eje fundamental de toda reconstrucción del pasado. Memoria significaría entonces dos cosas diferentes aunque muy relacionadas entre sí:

En primer lugar, sería el receptáculo de un pasado concreto que ha pervivido bajo el signo de la marginalidad, en testimonios, relatos y fuentes muchas veces 
orales - «las voces múltiples y desorganizadas»—-, o escasamente atendidas e incluso ignorados por la historiografía, tales como una ruina, un antiguo centro de tortura o una fosa común. Equivaldría a lo que habitualmente se entiende por «memoria histórica», focalizada en el pasado «de los marginados y excluidos», el cual no es necesariamente fáctico. Más bien al contrario, se trata de un pasado significado en la ausencia, el fracaso y el silencio, en la realidad que no ha alcanzado el «status» de lo fáctico y en la subjetividad anónima de los «sin nombre», según una expresión benjaminiana ${ }^{15}$, lo cual exige una especial agudeza hermenéutica del historiador que quiera rescatarlo.

Esa agudeza nos introduce directamente en el segundo de los significados referidos. Conforme a él, la memoria tendría también una significación metafórica y aludiría a una manera singular de entender el conocimiento histórico, el cual gravitaría en torno a ese pasado excluido, erigido en clave hermenéutica primordial de toda interpretación del pasado. En realidad, cuando la memoria plantea una aproximación al pasado diferente a la de la historia, está exigiendo otra manera de concebir esta última más que algo ajeno a ella. Por eso debemos hablar de «historia anamnética» o de una historia inspirada en el potencial crítico y hermenéutico de la memoria, más que de «memoria histórica», aun cuando haya sido este último término el que mayormente haya recogido y expresado dicho potencial, y aun cuando se solape con ella en algunos momentos. El propio Benjamín titula sus célebres tesis sobre la memoria Sobre el concepto de historia, a sabiendas de que lo que está en juego es otra manera de entender esta última y no sólo una reivindicación de aquélla. Otra manera, que esté dispuesta a rehabilitar la misma «condición originaria de la historia como recor- dación» que la historia positiva ha extirpado en nombre del «concepto moderno de ciencia.» ${ }^{16}$ «Científica» o no - ello dependerá de qué entendamos por ciencia-, esa recordación exige el despliegue de un tacto muy particular a la hora de relacionarse con el pasado, en virtud del cual éste es reconstruido a partir de sus ausencias y olvidos más que de sus acontecimientos, su esplendor cultural y sus documentos oficiales. O en virtud del cual estos últimos sean interpretados atendiendo a lo que Le Goff denomina sus «condiciones de producción»; es decir, reconociendo y descifrando el «poder sobre la memoria futura» y «el poder de perpetuación» que los grupos dominantes de su época y los «decidores de historia» les han conferido. Por eso habrá de aplicarse también «a la ausencia de documentos» y «a los silencios de la historia» ${ }^{17}$, preguntándose qué significan, cómo y dónde se han expresado y qué rastros han dejado; desplegando asimismo una singular agudeza para escuchar e interpretar «las voces múltiples y desorganizadas» que han sido excluidas de los regímenes discursivos instituidos por las convenciones historiográficas.

La tarea del historiador educado en la memoria es por tanto doble: hace presente el pasado ausente y desmitifica el pasado que fue erigido en presente, construye un pasado inédito y deconstruye el ya sabido, busca fragmentos de tradiciones derrotadas y cuestiona la teleología implícita en las tradiciones consumadas, aporta un conocimiento de experiencias que han sido escatimadas por la historiografía científica y reconstruye el pasado que las engloba bajo una lente más crítica que sustituye sus narraciones canónicas por otras discontinuas y fragmentadas, que han sido invisibilizadas. Benjamin emplea numerosas expresiones para referirse a esta capacidad de recordación. Una de ellas es la que la equipara a una 
hermenéutica capaz de «leer lo que nunca fue escrito», interpretando el pasado excluido del reino de la facticidad como si se tratara de un texto vivo, dotado de fuerza interpeladora ${ }^{18}$. Otra es el símil de un «trapero» que busca utopías fracasadas entre los restos de la cultura dominante o que «al alba, malhumorado, empecinado y algo borracho, se afana en pinchar con su bastón cachos de frases y trapos de discursos que echa en la carretilla, no sin agitar a veces en el ambiente de la mañana con gesto desaliñado algún trozo de paño desteñido llámese humanismo, interioridad o profundidad» ${ }^{19}$. En las tesis, identifica sobre todo ese método de recordación con la visión de un «materialista histórico» que se ha apropiado de Marx reemplazando todas sus concesiones a la lógica del progreso por un mesianismo secularizado de inspiración judía. Por eso «considera tarea suya cepillar la historia a contrapelo» ${ }^{20} \mathrm{y}$ descubrir en la insignificancia del pasado relegado «una oportunidad revolucionaria» para suspender el continuo de la historia o «hacer saltar una determinada época» de su «curso homogéneo», así como «una determinada vida, de una época; y una determinada obra, de entre toda la actividad laboral de una vida» ${ }^{21}$.

Esos textos nunca escritos y esos paños desteñidos e insignificantes son potencialmente revolucionarios porque, lejos de recrearse en la anécdota, identifican una herida del pasado que al hacerse visible altera el significado del universo que le rodea, posibilitando su transformación. Benjamín la equipara a una «mónada», pero no porque sea un microscosmos de la totalidad de la que fue desprendido, sino porque lleva dentro de sí la posibilidad de una historia universal sin exclusiones, frente al universalismo particularista y reaccionario del historicismo, el cual no produce nada nuevo y reduce la realidad al horizonte significativo de los grandes acontecimientos. En un caso se juzga el todo por la parte, en el otro la parte por el todo. No es lo mismo, en este sentido, reconstruir la historia de una comunidad o una nación considerando sus exilios como accidentes que no alteran sus identidades y narraciones dominantes, que hacerlo reconociendo en cada uno de ellos una pérdida o un pasado insatisfecho que cuestiona esas identidades y narraciones. Para un historiador conformista, cada exilio será un episodio del pasado, doloroso pero finiquitado, que, una vez explicadas sus causas, analizadas sus cifras y estudiadas sus dimensiones sociales y culturales, podrá incorporarse al relato global del que un día quedó desprendido, sin romper por ello sus continuidades. Para el historiador anamnético, por contra, cada exilio será una ausencia que cuestiona e interrumpe ese relato y obliga a escribirlo de nuevo desde el punto de vista de sus omisiones y olvidos.

Todo ello nos encamina hacia un rasgo primordial de la historia anamnética como es la responsabilidad política y moral del historiador, más allá del rol educador que tradicionalmente se le ha atribuido por su capacidad para extraer lecciones del pasado. «Historia magistra vitae», se ha repetido muchas veces para subrayar la capacidad del hombre para aprender de sus errores cometidos en el pasado, en el camino hacia su éxito civilizador. Sin embargo, las lecciones que la memoria quiere extraer del pasado para el presente son de otra índole. Si aceptamos que el pasado excluido no es insignificante pese a no formar parte del reino de «los hechos tal y como fueron», o que no es fruto de una lógica inevitable y naturalizada en la que poco ha tenido que ver la acción humana, su olvido será una injusticia y su memoria un deber. Rehabilitar ese pasado será entonces un imperativo no sólo epistemológico sino también moral, porque obliga a cuestionar cada 
presente construido sobre las ruinas y los escombros de ese pasado, advirtiendo la perdurabilidad de lo que significan, aunque sea bajo la forma de la ausencia o la «espectralidad». ${ }^{22}$ Contar la historia desde el punto de vista de los vencidos no será sólo, por tanto, una cuestión de objetividad o de fidelidad a la verdad, sino también de responsabilidad y de justicia, pues afecta a la herencia del pasado y su relevancia para la convivencia en el presente. Una memoria responsable de la represión franquista y del exilio republicano español, por ejemplo, no sólo aportará conocimiento sobre sus víctimas, sino que también estará llamada a cuestionar el presente que sucesivamente se ha ido construyendo sobre su olvido, advertirá que esas víctimas también formaron parte de dicho presente y que las insuficiencias de la democracia posterior han estado relacionadas con ese olvido.

La memoria crítica rescata así la significación práctica del pasado, al tiempo que señala los intereses del presente que han condicionado su olvido y desenmascara el carácter supuestamente apolítico que a menudo reivindica para sí el historiador científico bajo el mito de la objetividad fáctica. Ilumina así las conexiones entre ciencia e ideología, saber y poder, historia y mito, que han sido suplantadas por aquellas otras entre conocimiento y neutralidad, fracaso y naturaleza, memoria y autoridad pre-crítica, interrumpiendo el círculo que permanentemente se abre y se cierra entre la reificación del pasado y la deificación del presente. A la empatía que nace de esta circularidad opone aquella otra inspirada en la conciencia de un presente indigente y amenazado por la experiencia del sufrimiento, que aspira a «encender en lo pasado la chispa de la esperanza» ${ }^{23}$ para transformar ese presente y para que el futuro no sea una continuación de lo mismo o una reproducción conformista de lo ya dado.
Plantea así un encuentro dialéctico entre la imagen de un pasado oculto e inédito, latente e interpelador, y un sujeto necesitado «que se sabe no-sujeto» ${ }^{24}$, lo cual ofrece una especial dificultad puesto que esa imagen siempre correrá el peligro de ser instrumentalizado por los intereses dominantes en el presente o de «desaparecer con cada presente que no se reconozca mentado en ella» ${ }^{25}$. De ahí la angustia del historiador anamnético cuando quiere captar esa imagen porque lo que está en juego con ella «es algo más que conocer, algo más que añadir un apartado nuevo a la vieja historia de la humanidad, algo más que enriquecer los anaqueles de la biblioteca con un nuevo tratado.» ${ }^{26}$. Ese «algo más» consiste en un «acto redentor» que salve el sentido del pasado y transforme el presente. «Ni el presente-dado es todo el presente, ni el pasado-almacén es todo el pasado. Hay un presente-posible y un pasado-oculto. La tarea del historiador es hacer realidad el presente posible gracias a la presencia del pasado oculto.» 27

3. La experiencia del exilio constituye una fuente primordial de inspiración para cualquier planteamiento anamnético de la historia, por razones obvias. Todo pasado relegado, ausente u oculto es exiliado de alguna manera, ya sea en sentido literal o metafórico. De una forma u otra, se trata de un pasado que ha sido excluido de la historia tal y como ha sido reconstruida por las narraciones convencionales, oficiales, conformistas, canónicas y científicas, o que ha sido incorporada a ellas desde el punto de vista de los «hechos», de las memorias dominantes o de los patrimonios culturales más boyantes. Asimismo, el exilio, tan ligado siempre a la violencia, la guerra y - si nos ubicamos en el siglo XX - la crisis profunda de la racionalidad moderna incluidas sus maneras de entender el tiempo histórico, ha sido una experiencia que ha desperta- 
do la necesidad de una relación anamnética con el pasado ${ }^{28}$. Las tesis de Benjamin, sin ir más lejos, fueron maduradas al hilo de esta experiencia. El exilio es una especie de imán que atrae al pasado oculto y al presente indigente cuando se están buscando el uno al otro.

El exilio constituye así una figura de especial relevancia para elaborar, no sólo una crítica del espacio político moderno, tal y como ha mostrado Agamben, entre otros ${ }^{29}$, sino también del tiempo con el que se han construido las historias de ese espacio. En este sentido, sería fruto y expresión tanto de las codificaciones geopolíticas implicadas en la figura del Estado-nación, como de las narraciones que este último necesita para sostenerse y para concurrir en el espacio beligerante abierto por la soberanía moderna. Nación y narración constituyen así sus dos grandes coordenadas espacio-temporales. Si toda identidad nacional, en tanto que expresión colectiva del individuo moderno, nace —según Arendt- con el reverso amenazante de la identidad extranjera como símbolo de lo que hay que negar ${ }^{30}$, la nueva ciencia histórica estará llamada a reconstruir el pasado en consonancia con esa identidad en juego. Si el precio de lo primero es la exclusión, lo segundo se salda con el olvido. Como dijera en su día Renan, «la esencia de una nación es que todos los individuos tengan muchas cosas en común», pero «también que todos hayan olvidado muchas cosas» ${ }^{31}$. La nación condicionará así la construcción de la historia, incluso aquélla de vocación universal, delatando por cierto el universalismo particularista propio de la razón moderna europea - una cierta retrospectiva de la nación cristiano-germánica y una filosofía de la historia universal se solapan, si es que no se identifican, por ejemplo, en las Lecciones sobre filosofía universal de Hegel-. De manera inversa, aquella construcción heterodoxa o no convencional de la historia, por su recurso a la memoria, se verá abocada a polemizar con las identidades nacionales dominantes. Por poner un ejemplo, quizá no sea casual que una historiografía heterodoxa por su recurso a la memoria literaria, como la que pone en juego Américo Castro a propósito de la España medieval, alumbre otras genealogías de lo hispánico diferentes de aquéllas que gozan de un estatuto canónico, avalado por una historiografía de inspiración positivista.

En cualquier caso, el exilio es el no-lugar de la modernidad y también la expresión de sus omisiones narrativas. Es un continente apátrida y también un intervalo arrancado de la lógica lineal, diacrónica y amnésica que define al tiempo histórico de esa modernidad y contra la que se rebela. El exilio es el lugar del pasado excluido y por eso es el remanso de un tiempo que interrumpe y asalta esa lógica, alterándola e introduciendo en ella algo nuevo que posibilita que el futuro no sea una repetición de lo mismo. Es el tiempo de la no-identidad y por tanto es alteridad radical, tal y como han planteado, bajo matices diversos, autores como Jean Luc Nancy, Maurice Blanchot, Primo Levi, Emmanuel Levinas o Franz Rosenzweig. ${ }^{32}$ Una exiliada emblemática como María Zambrano expresa también esta conexión entre alteridad e interpelación, temporalidad e interrupción cuando en Los bienaventurados sostiene que el exiliado es "él mismo ya a su paso, una especie de revelación que él mismo puede ignorar, e ignora casi siempre como todo ser humano que es conducido para ser visto cuando él lo que quiere es ver. Pues que el exiliado es objeto de mirada antes que de conocimiento, (...) que es como decir de escándalo». O cuando sostiene que es «el devorado, el devorado por la historia» o por «El Tiempo», que es «Dios de la visión (...)». ${ }^{33}$ Es la pre- 
sencia de lo que siempre está ausente y por eso interpela hasta el punto de que su subjetividad consiste en ofrecerse como transparencia interruptora de esa ausencia.

En el caso de Zambrano, el exilio es también un itinerario interior ligado a la mística y a un singular gnosticismo ${ }^{34}$ que en algunos momentos pareciera inmovilizar su proyección secular ${ }^{35}$, aunque sin llegar a anularla ${ }^{36}$. El vínculo zambraniano entre religión y política es a veces difuso y tiende en ocasiones a acentuar lo primero sobre lo segundo, pero no por ello desaparece. Por eso Zambrano se fija en una figura del exilio de tan marcada significación política y cívica como Antígona, cuya agonía en los ínferos de Tebas es «vida y visión en el speculum justitiae» ${ }^{37}$ y revelación de «la Nueva Ley» ${ }^{38}$, mientras que en su «Carta sobre el exilio» de 1961, la mística del exiliado se entrelaza con una interpelación política, a manera de ofrenda, a las nuevas élites inconformistas de la España del interior, que están pensando en reformar el régimen al margen del exilio que ha generado. El exiliado - apunta Zambrano en esta carta- está más cerca «de ser criatura de la verdad que personaje de la historia» y se ha quedado al borde de la misma, «en el lugar sin nombre donde han estado siempre todos los dejados, por siglos a veces, para que alguien los recoja. (...) Y está así, embebido en paz y sosiego infinito, en un indecible olvido, porque no se ha quedado para que lo salven a él (...), sino para que quien lo recoja en el momento en que deba ser, reciba algo que sólo él tiene». Para «que le dejen dar, dar lo que nunca perdió y lo que ha ido ganando: la libertad que se llevó consigo y la verdad que ha ido ganando en esta especie de vida póstuma que se le ha dejado». ${ }^{39}$

En cualquier caso, si el exilio es la experiencia en la que se significa el tiem- po-otro o lo otro de la historia, su relación con la memoria tendrá que ser muy estrecha, además de plural. El exilio es la casa de la memoria y constituye un lugar privilegiado para pensar las tensiones entre ésta y la historia. Una manera muy común de entender dicha relación es aquélla que define la memoria como el vínculo psicológico y existencial que el sujeto exiliado - ya sea individual o colectivo- mantiene con el pasado del que ha sido violentamente separado y que nunca podrá recobrar, alterando su identidad, dejándola en una especie de suspenso y forjando la creación de otras identidades nuevas, paradójicas y fluctuantes entre la inserción y el desarraigo, la integración y la exclusión ${ }^{40}$. La memoria exiliada se caracteriza entonces por su ambigüedad. Por una parte, es susceptible de derivar hacia el ensimismamiento, de replegarse en el pasado e incluso de recurrir a una mitificación interesada del mismo ${ }^{41}$. Esto es ciertamente innegable, como no pocas veces se ha repetido. Pero, por otra parte, la memoria exiliada puede propiciar también un conocimiento de ese pasado perdido que escapa a la mirada del historiador convencional y que cuestiona los paradigmas metodológicos de los que este último se nutre. Una cierta historia anamnética se despliega en este sentido en el ensayo autobiográfico de María Zambrano Delirio y destino. Los veinte años de una española escrito entre 1951 y 1953, durante su exilio en Cuba, poco después de que la dictadura de Franco empezara a gozar de un reconocimiento internacional formal. Es decir, en pleno olvido del exilio republicano español del que ella siempre formó parte.

Inédito hasta $1988^{42}$ y editado en su versión íntegra diez años después ${ }^{43}, D e-$ lirio y destino pertenece a eso que la propia Zambrano denominara «confesión», entendida no sólo como un género literario o una memoria testimonial, sino tam- 
bién como un método filosófico característico de la «razón poética». Los términos «delirio»y «destino» aludirían en este sentido a un mismo pasado, pero susceptible de ser reconstruido de dos maneras diferentes e incluso antagónicas. Por una parte, el pasado de la memoria, ligado a la semántica de la redención; por otro, el de la historia, ligado a la lógica externa de los acontecimientos. En medio de esta tensión, Zambrano evoca las dos décadas transcurridas entre 1928 y 1948 , incidiendo sobre todo en los años 192831. Es decir, en el tiempo inmediatamente anterior a la proclamación de la Segunda República Española, en el momento de su advenimiento y de su gestación, el cual se hace presente no ya en el ámbito de los sucesos políticos, sino también - y sobre todo — de la vitalidad colectiva que los impregnó e hizo posibles. No tanto en el orden fáctico como en el de la memoria colectiva. Por eso cuando Zambrano evoca ese momento como un instante singular y extraordinario de la historia de España, no lo hace simplemente porque se aboliera la dictadura de Miguel Primo de Rivera y se proclamara un gobierno democrático y republicano. Lo hace más bien por la significación sub-histórica y anamnética, intangible para el historiador convencional, de esos y otros acontecimientos del momento. En concreto, porque a su juicio traducían el desencantamiento de los hechizos que hasta entonces habían presidido la historia de España, la interrupción de la inercia, el nihilismo y la fatalidad bajo la que esta historia había discurrido durante siglos, y el desahogo de una esperanza colectiva siempre truncada aunque latente. ${ }^{44}$

Delirio y destino despliega así una memoria doble. Por una parte, está haciendo presente un pasado ausente, como es el proyecto democratizador de la $\mathrm{Se}$ gunda República, relegado al olvido, sal- vo excepciones, por la comunidad internacional. Como dirá en 1977, a contrapelo esta vez del olvido inscrito en la transición española a la democracia, está apelando a un «entonces» que «sigue siendo todavía por haber sido vivido tan verdaderamente, sin regateo alguno»y que es «razón germinativa, germinante en lo escondido de la historia» ${ }^{45}$. Al mismo tiempo y de manera más explícita, está descifrando la significación anamnética de ese proyecto, en tanto que comparecencia de múltiples pasados de la historia de España que permanecían relegados a la oscuridad. Esa comparecencia exigirá una temporalidad compleja y singular, fluida e irreductible a la linealidad historicista, y abierta a la confluencia de múltiples tiempos reprimidos que van tejiendo una trama polifónica de relaciones culturales, políticas y sociales. Convergen así las evocaciones de la biografía personal de la autora; de la generación estudiantil a la que perteneció y de las relaciones de esta última con los intelectuales de la época, empezando por Unamuno y Ortega - cuyos respectivos conceptos de «intrahistoria» y «razón histórica» son, por cierto, llevados más allá de sí mismos en esta evocación autobiográfica-; asimismo, una reflexión sobre España a través de múltiples motivos, episodios, perfiles y conflictos - los suicidios de Larra y Ganivet en el XIX, la novela de Galdós, la pintura de Velázquez, Zurbarán o Juan Gris, el krausismo, el retraimiento de Felipe II...; una cierta filosofía de la historia según la cual ésta habría discurrido en Occidente en un sentido sacrificial; y una peculiar sociología del Madrid de entonces capaz de leer en sus expresiones cotidianas el resurgimiento de una vitalidad oculta y latente -Zambrano hablará en este sentido de un Madrid «marino», en el que emergen ámbitos sumergidos de la historia de España-. 
La confluencia de todos esos elementos despeja la significación del advenimiento republicano como un momento «auroral», en el que se desahogan tiempos no vividos y se alumbra «una historia verdadera» ${ }^{46} \mathrm{o}$ "sin serpiente» ${ }^{47}$, en la que la historia de los últimos siglos, simbolizada en la monarquía, resulta abolida. Es decir, dicha significación no se substanciaría sólo en un proyecto de incorporación de España a la modernidad y de consumación de una ilustración pendiente, tal y como lo narraría la historia científica, sino también en la resolución de aquellos nudos y conflictos que habían congestionado la historia de España, reducida durante siglos a una suerte de inercia o de pulso muerto y elevada ahora «a su claridad en un raro instante»; en la redención de sus infiernos, de sus sujetos anónimos y sus intelectuales suicidas, en la «asunción de lo condenado al pasado a la luz del presente» ${ }^{48}$ o en el «examen de conciencia que lo pasado no puede hacer allá en su infierno, ignorante como está de las consecuencias que nos trajeron sus yerros» ${ }^{49}$. En definitiva, en el desencantamiento de Dulcinea ${ }^{50}$, cuya figuración cervantina no había sido sino expresión, al fin y al cabo, de ese pulso muerto. Bajo la lente de la memoria, la República personificaba a un «huésped que se espera cuando se aproxima a nuestra puerta» 51 .

Pero no olvidemos el contexto de estas evocaciones, escritas en 1951, en un momento en el que el «destino» se había impuesto y el «delirio» podía ser una expresión de rebeldía contra él. En una carta dirigida a Rosa Chacel en 1953, Zambrano aludía a los «delirios» como «lo que nos han dejado (...): la verdad en un esqueleto. Y los esqueletos obligados a vivir» — proseguía- «deliran». ${ }^{52}$ Delirio es entonces la voz interruptora del vencido que no ha muerto o de quien lleva consigo el testimonio de sus muertos. En Delirio y destino, Zambrano había evocado a los suyos, a los sacrificados durante la guerra y a los suicidas del destierro, concluyendo con un «Sí; os comprendo, os comprendo». ${ }^{53}$ También por esos años, Zambrano preparaba uno de sus libros fundamentales, El hombre y lo divino (1955), en el que se refería al delirio a propósito del significado de las ruinas. «No hay ruina - afirmaba - sin vida vegetal; sin yedra, musgo o jaramago que brote en la rendija de la piedra, confundida con el lagarto, como un delirio de vida que nace de la muerte». ${ }^{54}$ Para Zambrano, una ruina no es una masa muerta por obra del destino o el resto de un pasado al que accederemos si reconstruimos sus acontecimientos «tal como fueron», sino «lo que ha sobrevivido a su destrucción» o aquello

«cuyo derrumbe material sirve de soporte a un sentido que se extiende triunfador; supervivencia, no ya de lo que fue, sino de lo que no alcanzó a ser. Por las ruinas se aparece ante nosotros la perspectiva del tiempo, de un tiempo concreto, vivido, que se prolonga hasta nosotros y aún prosigue. (...) Tiempo de un pasado que lo sigue siendo, que se actualiza como pasado y que muestra, al par, un futuro que nunca fue $(. .)$.$» .$

Ruina - prosigue Zambrano- es «traza de algo humano vencido y luego vencedor del paso tiempo. (...) Algo que nunca fue enteramente visible», que «tiene algo de intento frustrado» y que lleva dentro de sí «la realidad perenne de lo frustrado; la victoria del fracaso» ${ }^{55}$. Es decir, la ruina sería el vestigio de un pasado marcado por el fracaso, irreductible a algo fáctico, portador de un significado inagotable que alcanza al presente y abre posibilidades de futuro, y evocador de algo humano que se resiste a ser naturalizado. Por eso en el lugar donde se asienta la ruina, la muerte puede transformarse en un delirio de vida, algo que Zambrano identifica con «lo propiamente histórico», que «no es ni el hecho 
resucitado con todos sus componentes (...), ni tampoco la visión arbitraria que elude el hecho, sino la visión de los hechos en su supervivencia, el sentido que sobrevive tomándolos cuerpo». ${ }^{56} \mathrm{~A}$ comienzos de los años cincuenta, Zambrano esbozaba así, a propósito de su reflexión sobre las ruinas y en conexión con el significado del delirio, una teoría del conocimiento histórico de tendencia anamnética que se desmarca de la concepción «objetiva» del pasado, según la cual éste se reduce a «lo que se ha hecho, con ese carácter impersonal que lo ave- cina a la naturaleza y que ha sido llamado destino», y que se identifica más bien con una concepción poética y trágica, cuya finalidad es «transformar el acontecimiento en libertad»y «rescatar la esperanza de la fatalidad». Para Zambrano, ambas concepciones se orientan en función de dos preguntas bien diferentes: «¿qué son las cosas?» en un caso, «¿qué es lo que me han hecho?» ${ }^{57}$ en el otro. Responder a alguien que se pregunta esto último puede ser, por tanto, el punto de partida de una historia inspirada en la memoria.

\section{NOTAS}

1 Cubitt, G., History and memory, Manchester University Press, 2007, p. 2.

2 Ibid., pp. 29s.

3 «Aceleración de la historia. Más allá de la metáfora, es necesario calibrar lo que esta expresión significa: un vaivén cada vez más rápido en un pasado definitivamente muerto, la percepción global de cualquier cosa como desaparecida - una ruptura de equilibrio. (...) La curiosidad por los lugares donde re cristaliza y se refugia la memoria está ligada a este momento particular de la historia. Momento clave, en el que la conciencia de ruptura con el pasado se confunde con el sentimiento de una memoria desgarrada: pero en el que el desgarramiento también despierta la memoria necesaria para que pueda plantearse el problema de su encarnación. (...) Este desmoronamiento de la memoria no es más, sin embargo, que un ejemplo. Es el mundo entero el que ha entrado en liza por el fenómeno bien conocido de la mundialización, la democratización, la masificación, la mediatización.» Cf. Norá, P., «Entre mémoire et histoire. La problematique des lieux», en Les lieux de la mémoire (sous la direction de Pierre Norá), 3 vol., Paris, Gallimard, 1997, vol. I, p. 23.

4 De la magnitud y complejidad de este cambio epocal ha dado buena cuenta la obra de Reyes Mate. Cf., por ejemplo, Memoria de Auschwitz. Actualidad moral y politica, Madrid, Trotta, 2003; Medianoche en la historia. Comentarios a las tesis de Walter Benjamin Sobre el concepto de historia, Madrid, Trotta, 2006; Tratado de la injusticia, Barcelona, Anthropos, 2011.

5 «Es preciso situarse en la problemática de los tiempos del testigo y de su interlocutor, y en la del tiempo presente, y analizar los sucesivos ecos de aquel acontecimiento hasta llegar al hoy.» $\mathrm{Al}$ conocimiento «objetivo» del pasado «es preciso añadir el conocimiento de la percepción presente del pasado. Este presente del pasado es precisamente la memoria», apunta Josefina Cuesta en La odisea de la memoria. Historia de la memoria en España. Siglo XX, Madrid, Alianza Editorial, 2008, p. 48.

${ }^{6} \mathrm{Me}$ refiero con este término a una concepción del pasado historicista en sentido amplio. Peter Burke define el "“paradigma tradicional" de la historia por su inspiración rankeana; su pretendida identificación con el sentido común; su interés por la narración de acontecimientos, especialmente las grandes hazañas y las acometidas por personalidades célebres; y su pretensión de objetividad, basada sobre todo en documentos de carácter oficial». Cf. Burke, P., «Obertura: la nueva historia, su pasado y su futuro», en Burke, P. (ed.), Formas de hacer historia, Madrid, Alianza, 1993, pp. 11-19.

7 Así lo resume Paloma Aguilar en Políticas de la memoria y memorias de la política, Madrid, Alianza, 2008, pp. 63s.

8 Así lo han enfatizado numerosos cultivadores de la Nueva Historia Cultural desde bagajes y perspectivas diversos, tal y como expone resumidamente Peter Burke en ¿Qué es la historia cultural?, Barcelona, Paidós, 2006, pp. 97-124. Ya en 1933, en un discurso pronunciado en el Collège de France, Lucien Febvre expresaba de una manera básica esta idea: «No dado, sino creado por el historiador — ¿y cuántas veces? Inventado y fabricado mediante hipótesis y conjeturas, a través de un trabajo delicado y apasionado. (...) Elaborar un hecho significa construirlo.» Citado por J. Le Goff, Pensar la historia. Modernidad, presente, progreso, Barcelona, Paidós, 1991, p. 34.

9 Histoire et mémoire, Paris, Gallimard, 1986, p. 11 . 
10 Hobsbawm, E. J., La era del Imperio (1875-1914), Barcelona, Labor, 1989, pp. 2ss.

11 Le Goff, Histoire et mémoire, cit., p. 10.

12 Cf. Ricoeur, P., La memoria, la historia, el olvido, Madrid, Trotta, 2003.

13 Norá, P., op. cit., pp. 24s.

14 Cubitt, G., op. cit., p. 36.

15 «Es más difícil honrar la memoria de los sin nombre que la de los famosos, de los célebres, sin exceptuar a poetas y pensadores. A la memoria de los sin nombre está consagrada la construcción histórica.» Benjamín, W., «Materiales preparatorios del escrito Sobre el concepto de historia», en Mate, R., Medianoche, cit., p. 314.

16 Ibid., p. 306.

17 Le Goff, Pensar la historia, cit., pp. 107s.

18 «El método histórico es un método filológico y a ese método subyace el libro. Leer lo que nunca fue escrito, se dice en Hofmannstahl. El lector en el que conviene pensar aquí es el historiador verdadero.» Benjamín, W., «Materiales preparatorios del escrito Sobre el concepto de historia», en Mate, R., Medianoche, cit., p. 313.

19 Benjamin, W., Gesammelte Schrifte, Ed. de R. Tiedemann y H. Schweppenhäuser, con la colaboración de Th. W. Adorno y G. Ssholem, Frankfurt am M., Surkhamp. 1972ss, III, p. 225. Citado por Mate, R. en Medianoche, cit., p. 33.

20 Benjamin, W., «Sobre el concepto de historia», Tesis VII, en Mate, Medianoche, cit, p. 130. Cf. el comentario de Reyes Mate a esta tesis en las pp. 130-141.

21 Benjamín, W., «Sobre el concepto de historia», Tesis, XVII, en Mate, Medianoche, cit., p. 267. Sobre este punto, cf. también la Tesis XVI y los comentarios de Reyes Mate en las pp. 249-274.

22 Mari Paz Balibrea alude a este término derridiano «como forma inescapable en que el pasado habita críticamente en el presente». Cf. Balibrea, M. P., Tiempo de exilio. Una mirada crítica a la modernidad española desde el pensamiento republicano en el exilio, Montesinos, 2007, p. 94.

23 Benjamin, W., «Sobre el concepto de historia», Tesis VI, en Mate, Medianoche, cit., p. 113. Cf. el comentario de Reyes Mate a esta tesis en las pp. 113-128.

24 Mate, Medianoche, cit., p. 112.

25 Benjamin, W., «Sobre el concepto de historia», Tesis V, en Mate, R., Medianoche, cit., p. 107. Cf. el comentario de Reyes Mate a esta tesis en las pp. 108-128.

26 Mate, Medianoche, cit., p. 108.

27 Ibid., p. 110.

28 Un ejemplo de esta doble relación del exilio con la memoria - como objeto y como sujeto de la misma- puede encontrarse, a propósito del exilio español de 1939, en Balibrea op. cit. Cf. también mis trabajos «Memoria del exilio y exilio de la memoria», en Arbor, n. ${ }^{\circ} 735,2009$, pp. 3-11; «Perder la guerra, ga- nar la paz. Memoria republicana y crítica del presente», en Zamora, J. A. y Sucasas, A. (coords.), Memoria-política-justicia. En diálogo con Reyes Mate, Madrid, Trotta, 2010, pp. 163-181.

29 Cf. por ejemplo «Política del exilio», en Archipiélago, n. ${ }^{\text {os }} 26-27,1996$, pp. 41-52.

30 Cf. Arendt, H., «We Refugees», en Robinson, M. (ed.): Altogether elsewhere. Writers on exile. San Diego, Harcourt Brace, 1994.

31 Renan, E., ¿Qué es una nación?, Madrid, Centro de Estudios Constitucionales, 1983, p. 17.

$32 \mathrm{Cf}$. Mate, Tratado de la injusticia, cit., pp. 204-207.

33 Zambrano, M., Los bienaventurados, Madrid, Siruela, 2004, pp. 32ss.

34 Así lo ha mostrado Jesús Moreno Sanz en numerosos lugares. Recientemente, en «Destierro y exilio: categorías del pensar de María Zambrano», en Sánchez Cuervo, A. y Hermida de Blas, F., Pensamiento exiliado español. El legado filosófico del 39 y su dimensión iberoamericana, Madrid, Biblioteca Nueva-CSIC, 2010, pp. 268-322.

35 Así lo plantea Balibrea en op. cit.

36 Me he aproximado a la significación zambraniana del exilio en «Las metamorfosis del exilio», en Sánchez Cuervo, A.; Sánchez Andrés, A. y Sánchez Díaz, G., María Zambrano. Pensamiento y exilio, Madrid, Comunidad de Madrid-Morelia, UMSNH, 2004, pp. 173-190. Nueva edición en Madrid, Biblioteca Nueva, 2010, pp. 173-190.

37 Zambrano, M., «La tumba de Antígona», en Zambrano, M., Senderos, Barcelona, Anthropos, p. 213.

38 Ibid., p. 204.

39 Zambrano, M., "Carta sobre el exilio», en Cuadernos del congreso por la libertad de la cultura, $\mathrm{n}^{\circ}$ 49, 1961, pp. 67-70.

$40 \mathrm{Cf}$. por ejemplo el testimonio de un filósofo del exilio español de 1939 como Adolfo Sánchez Vázquez, en «Fin del exilio y exilio sin fin», en Sánchez Vázquez, A., Del exilio en México. Recuerdos y reflexiones, México, Grijalbo, 1997, pp. 35-38. También lo ha expuesto con amplitud y precisión Clara E. Lida, a propósito de este mismo exilio, en Caleidoscopio del exilio. Actores, memoria, identidades, México, El Colegio de México, 2009, pp. 67-95.

41 Así lo plantea Sebastian Faber a propósito del nacionalismo cultural mediante el que cierta inteligencia del exilio español de 1939 podía compensar y sublimar su derrota y su aislamiento, así como subrayar su legitimidad moral y su hegemonía cultural en tanto que interlocutora de la «auténtica España». Cf. Exile and cultural hegemony. Spanish intellectuals in Mexico, 1939-1975, Nashville, Vanderbilt University Press, 2002.

42 Madrid, Mondadori.

43 Edición completa y revisada por Rogelio Blanco Martínez y Jesús Moreno Sanz, Madrid, Centro de 
Estudios Ramón Areces-Fundación María Zambrano, 1998.

44 Sobre este ensayo de Zambrano, deben tenerse en cuenta los trabajos de Moreno Sanz, J., «La política desde su envés histórico-vital: historia trágica de la esperanza y sus utopías», Estudio introductoria a Zambrano, M., Horizonte de liberalismo, Madrid, Morata, 1996; y de Beneyto, J. M., «La multiplicidad de los tiempos. María Zambrano en diálogo con Reinhart Koselleck, Hans Blumenberg y Emmanuel Lévinas», en Beneyto, J. M. y González Fuentes, J. A., María Zambrano. La visión más transparente, Madrid, Trotta-Fundación Carolina, 2004, pp. 477-521.

45 Zambrano, M., «La experiencia de la historia (después de entonces)», en Senderos, cit., p. 15. Se trata del Prólogo a la edición de 1977 de Los intelectuales en el drama de España (1937).
46 Delirio y destino, ed. de 1998, p. 189.

47 Ibid., p. 220.

48 Ibid., p. 176.

49 Ibid., p. 179.

50 «Pues en aquella coyuntura histórica, los españoles se disponían a desencantar a Dulcinea; la esencia perdida, ofreciéndole su adecuada forma», p. 179.

51 Ibid., p. 182.

52 Cf. Moreno Sanz, J., Prólogo a Zambrano, M-, El hombre y lo divino, Madrid, Círculo de Lectores, 1999.

53 Delirio y destino, ed. de 1998, pp. 221s.

54 Zambrano, M., El hombre y lo divino, Madrid, FCE, 2007, p. 236.

55 Ibid., pp. $234 \mathrm{~s}$.

56 Ibid., p. 233.

57 Ibid., pp. 231s. 